\title{
Effect of Penicillin on Reproductive Function in Female Wistar Rats
}

\author{
Oyedeji K.O.*1, Momoh R.O. ${ }^{1}$, Oderinde Gbenga ${ }^{2}$ \\ 1. Department of Physiology, College of Medicine and Health Sciences, Afe Babalola University, Ado-Ekiti, Nigeria. \\ 2. Department of Anatomy, College of Medical Sciences, Ahmadu Bello University, Zaria, Nigeria. \\ *Corresponding author's E-mail: sinaoyedeji@yahoo.com
}

Received: 18-05-2021; Revised: 12-11-2021; Accepted: 21-11-2021; Published on: 20-12-2021.

\section{ABSTRACT}

This study was designed to investigate the effect of penicillin on reproductive function in female Wistar rats. Fifteen female rats (120 $-160 \mathrm{~g})$ were used for the estrous cycle and histopathological studies. Penicillin $(17.14 \mathrm{mg} / \mathrm{kg})$ was administered orally on daily basis for 21 and 50 days respectively for the estrous cycle and histological studies. Estrous cycle was carried out using the technique of Marcondes et al., histologies of the ovaries and uteri were also carried out. Data were analysed using descriptive statistics and student's t-test at $p=0.05$. Treatment of rats for 21 days with penicillin $(17.14 \mathrm{mg} / \mathrm{kg})$ produced significant $(p<0.05)$ increments in the estrous and metestrous phases as well as a significant $(p<0.05)$ reduction in the proestrous phase of the estrous cycle relative to their respective controls. The histopathological study presented with a moderate endometrial congestion. It can therefore be concluded that penicillin probably has a pro-fertility effect with a moderate deleterious effect on the uteri at histological level in female Wistar rats.

Keywords: Penicillin, Proestrous, Estrous, Ovaries, Rats.

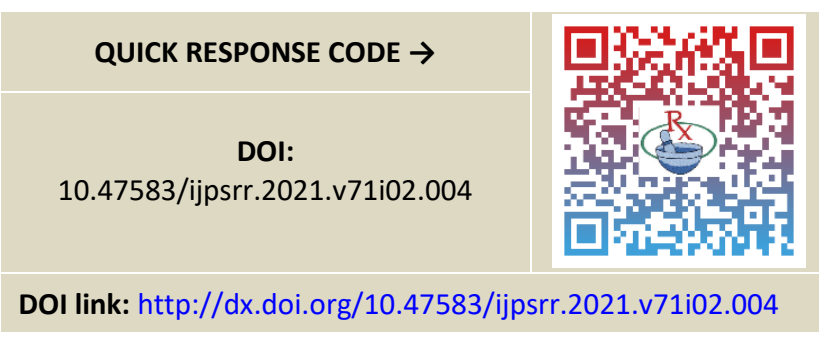

\section{INTRODUCTION}

$\mathrm{P}$

enicillins are a group of antibiotics originally obtained from Penicillium moulds, principally $P$. chrysogenum and $P$. rubens. Most penicillins in clinical use are chemically synthesised from naturallyproduced penicillins. A number of natural penicillins have been discovered, but only two purified compounds are in clinical use: penicillin $\mathrm{G}$ (intravenous use) and penicillin $\mathrm{V}$ (given by mouth). Penicillins were among the first medications to be effective against many bacterial infections caused by staphylococci and streptococci. They are members of the $\beta$-lactam antibiotics, which are some of the most powerful and successful achievements in modern science ${ }^{1}$. They are still widely used today for different bacterial infections, though many types of bacteria have developed resistance following extensive use.

Penicillin effect on the metabolome of rats has been reported ${ }^{2}$. It exhibits a degree of anxiolytic activity in rats ${ }^{3}$. The effects of repeated systemic penicillin injections on nonconvulsive and convulsive epileptic seizures in rats have been reported ${ }^{4}$. The effects of its orally given very large doses on collagen defects in rats has also been reported ${ }^{5}$. However, due to scanty information from literature on the effect of penicillin on reproductive parameters in female rats, this study therefore aims at investigating the effect of this antibiotic on these aforementioned parameters in female rats.

\section{MATERIALS AND METHODS}

\section{Experimental Animals}

Adult female rats weighing between $120 \mathrm{~g}-160 \mathrm{~g}$ bred in the Pre-Clinical Animal House of the College of Medicine and Health Sciences, Afe Babalola University were used. They were housed under standard laboratory conditions and had free access to feed and water; they were acclimatized for two weeks to laboratory conditions before the commencement of the experiments. All experiments were carried out in compliance with the recommendations of Afe Babalola University Ethics Committee on guiding principles on care and use of animals.

\section{Drug}

Penicillin injections (Yanzhou Xier Kangtai Pharmaceutical Ltd., China) were bought from Danax Pharmacy, Ibadan, Nigeria.

Penicillin injection $(600 \mathrm{mg}$ ) was dissolved in $10 \mathrm{ml}$ of distilled water to give a concentration of $60 \mathrm{mg} / \mathrm{mL}$.

The dosage of penicillin used in this study was in accordance with that reported by the manufacturer.

\section{Experimental Design}

\section{Study on Estrous Cycle}

Five matured female rats showing at least three regular 4 - 5 day cycles were used for this study. Vaginal lavages (smears) were examined microscopically every day at a 
constant interval of $4.30-5.30$ p.m. for 21 days before and after treatments with the antibiotic. The smears were classified into one of the phases of the estrous cycle using the Marcondes technique ${ }^{6}$. Vaginal secretion was collected with a plastic pipette filled with $10 \mu \mathrm{L}$ of normal saline ( $\mathrm{NaCl} 0.9 \%$ ) by inserting the tip into the rat's vagina, but not deeply. Vaginal fluid was placed on glass slide. One drop was collected with a clean tip from each rat. Unstained material was observed under a light microscope, without the use of condenser lens, with 10 and $40 \mathrm{x}$ objective lenses. Three types of cells could be recognized: round and nucleated ones are epithelial cells; irregular ones without nucleus are the cornified cells; and the little round ones are the leucocytes. The proportion (preponderance) among them was used for the determination of estrous cycle phases 7,8 . The duration of the estrous cycle was determined. In this study, the experimental animals also served as the control. The first 21 days served as the control days, while the last 21 days served as the treatment days. Each of the 5 rats for this estrous cycle study received $17.14 \mathrm{mg} / \mathrm{kg}$ of penicillin intraperitoneally (i.p.).

\section{Histopathological Study}

In another set of experiment, ten matured female rats divided into two equal groups (five animals per group) received the following treatments of the antibiotic (i.p.) and control (orally) per day for fifty days as follows:

Group I rats received $0.5 \mathrm{ml} / 100 \mathrm{~g}$ of distilled water as the control group.

\section{Group II rats received $17.14 \mathrm{mg} / \mathrm{kg}$ of penicillin.}

On the 51st day, all the rats were sacrificed by an overdose of chloroform. The ovaries and uteri were dissected out, cleaned of fat and immediately fixed in Bouin's fluid.

\section{Histological preparation of tissues}

After weighing the ovaries and uteri, they were immediately fixed in Bouin's fluid for 12 hours and the Bouin's fixative was washed from the samples with $70 \%$ alcohol. The tissues were then cut in slabs of about $0.5 \mathrm{~cm}$ transversely and the tissues were dehydrated by passing through different grades of alcohol: $70 \%$ alcohol for 2 hours, $100 \%$ alcohol for 2 hours, and finally $100 \%$ alcohol for 2 hours. The tissues were then cleared to remove the alcohol, the clearing was done for 6 hours using xylene. The tissues were then infiltrated in molten paraffin wax for 2 hours in an oven at $57^{\circ} \mathrm{C}$, thereafter the tissues were embedded. Serial sections were cut using rotary microtone at 5 microns $(5 \mu \mathrm{m})$. The satisfactory ribbons were picked up from a water bath $\left(50-55^{\circ} \mathrm{C}\right)$ with microscope slides that had been coated on one slide with egg albumin as an adhesive and the slides were dried in an oven. Each section was deparaffinized in xylene for 1 minute before immersed in absolute alcohol for 1 minute and later in descending grades of alcohols for about 30 seconds each to hydrate it. The slides were then rinsed in water and immersed in alcoholic solutions of hematoxylin for about 18 minutes.
The slides were rinsed in water, and then differentiated in $1 \%$ acid alcohol and then put inside a running tap water to blue and then counterstained in alcoholic eosin for 30 seconds and rinsed in water for a few seconds, before being immersed in $70 \%, 90 \%$ and twice in absolute alcohol for 30 seconds each to dehydrate the preparations. The preparations were cleared of alcohol by dripping them in xylene for I minute. Each slide was then cleaned, blotted and mounted with DPX and cover slip, and examined under the microscope. Photomicrographs were taken at $x 40$ and x100 magnifications.

\section{Statistical Analysis}

The mean and standard error of mean (S.E.M.) were calculated for all values. Comparison between the control and the treated group was done using student's t-test. Differences were considered statistically significant at $p<0.05$.

\section{RESULTS}

Treatment of rats for 21 days with penicillin $(17.14 \mathrm{mg} / \mathrm{kg}$ ) produced significant $(p<0.05)$ increments in the estrous and metestrous phases as well as a significant $(p<0.05)$ reduction in the proestrous phase of the estrous cycle relative to their respective controls (Figure 1).

Treatment of rats with penicillin $(17.14 \mathrm{mg} / \mathrm{kg}$ ) for 50 days produced no pathological effects on the ovaries, which is similar to what was observed in the control rats (Plates 1 and 2).

Treatment of rats with penicillin $(17.14 \mathrm{mg} / \mathrm{kg})$ for 50 days presented with a moderate endometrial congestion contrary to what was observed in the control rats (Plates 3 and 4).

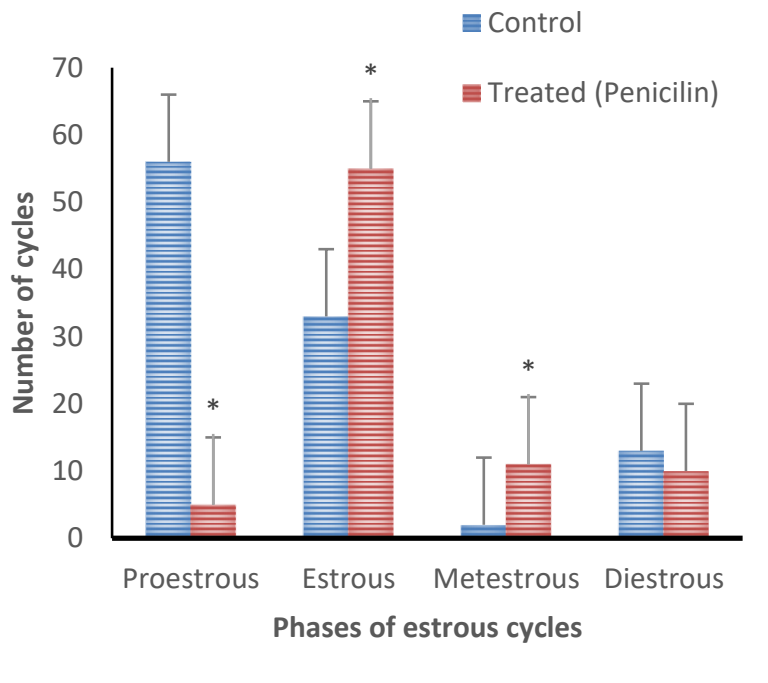

Figure 1: Effect of 21 days treatment with penicillin on estrous cycle ( $n=5, * p<0.05$ ) 


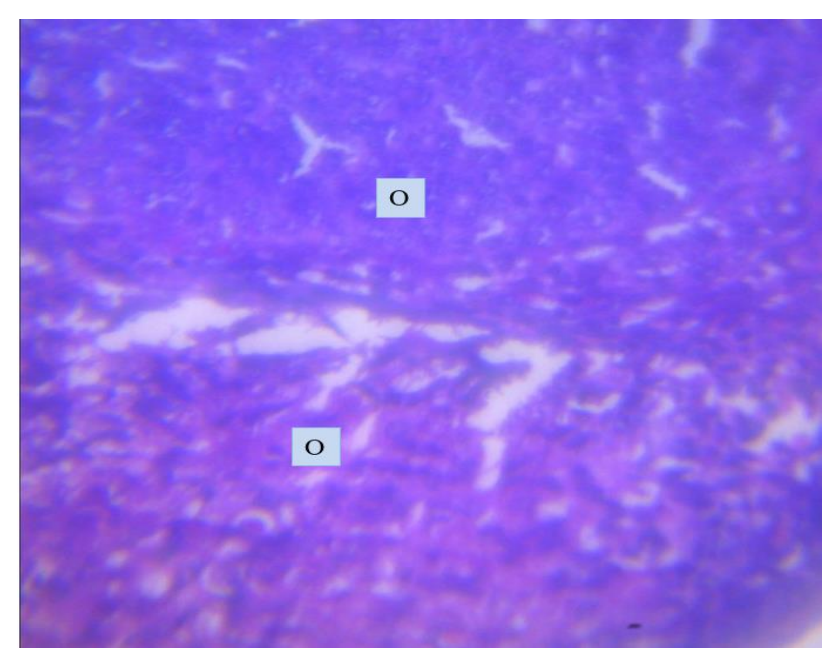

Plate 1: Effect of $0.5 \mathrm{ml} / 100 \mathrm{~g}$ distilled water (control) on the ovary at $x 400$. Photomicrograph showing a normal ovary (O) with no visible lesions seen.

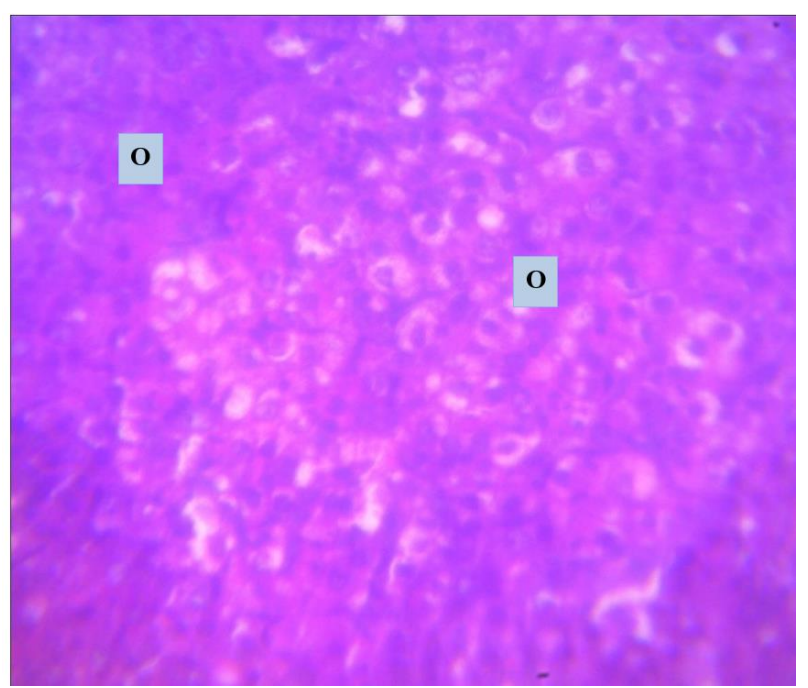

Plate 2: Effect of penicillin $(17.14 \mathrm{mg} / \mathrm{kg})$ on the ovary at $x$ 400. Photomicrograph showing an ovary (O) with no pathologic lesions seen.

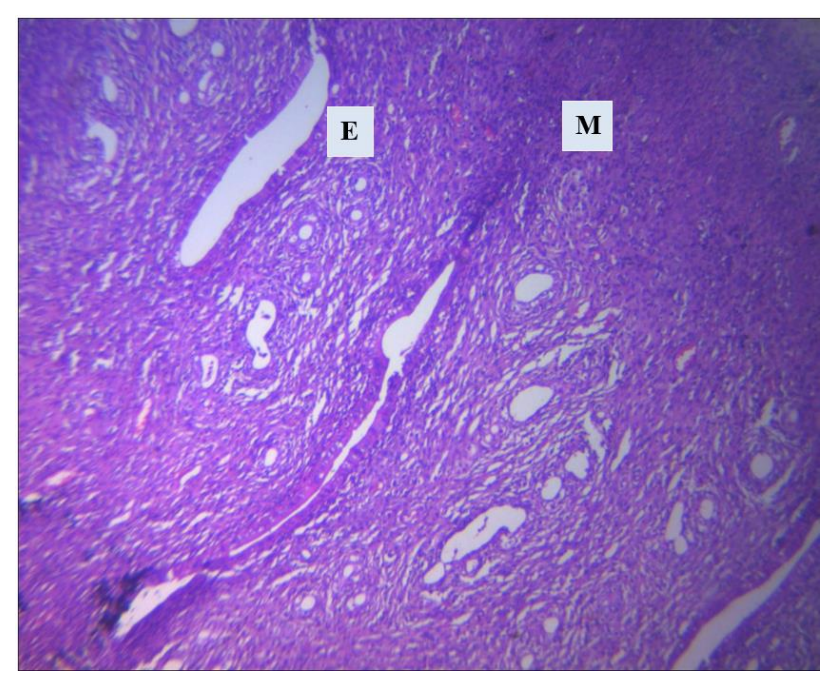

Plate 3: Effect of $0.5 \mathrm{ml} / 100 \mathrm{~g}$ distilled water (control) on the uterus at $x 400$. Photomicrograph showing normal endometria (E) and myometrium (M) with no visible lesions seen.

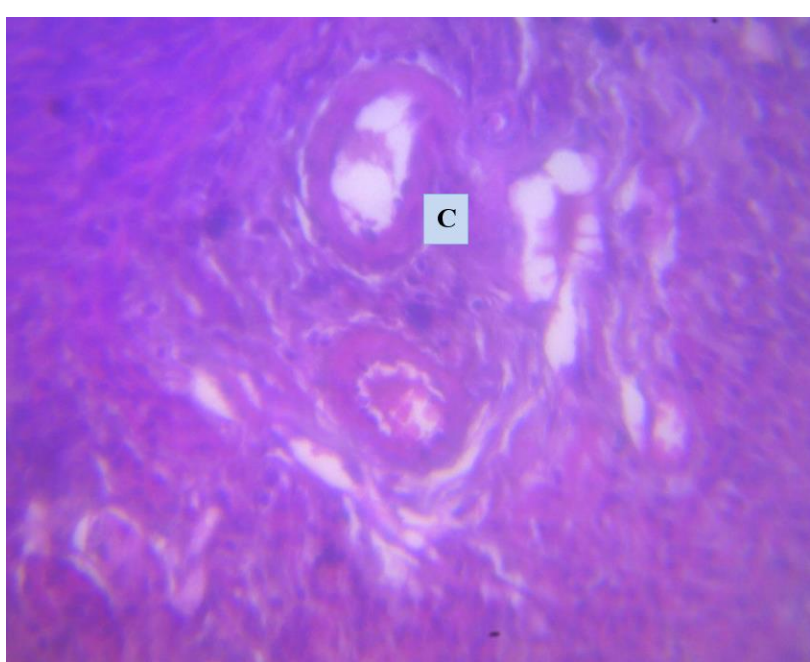

Plate 4: Effect of penicillin $(17.14 \mathrm{mg} / \mathrm{kg})$ on the uterus at $\mathrm{x} 400$. Photomicrograph showing moderate congestion (C) of the endometrium.

\section{DISCUSSION}

The estrous cycle study revealed that penicillin caused significant changes in the duration of different phases of the estrous cycle. Contrary report was given by ${ }^{9}$ in Portulaca oleracea extracts treated rats. This suggests that the antibiotic caused imbalances of the ovarian and extraovarian hormones, since it has been reported that imbalance in these hormones lead to irregularity in the ovarian functions and duration of the estrous cycle ${ }^{10}$.

Treatment of rats with penicillin caused significant decrease in proestrous phase of the estrous cycle which probably indicates that the maturation of the follicles in the preovulatory phase was hastened leading to maturation of the Graafian follicles. Contrary result was reported by ${ }^{11}$ in alcohol treated rats. Treatment of rats with penicillin caused significant increase in estrous phase of the estrous cycle which suggests the availability of matured Graafian follicles and would lead to ovulation. Similar result was reported by ${ }^{12}$ in alcohol treated rats. Also, treatment of rats with penicillin caused significant increase in metestrous phase of the estrous cycle which probably indicates the availability of matured Graafian follicles. Similar result was given by ${ }^{13}$ in tetracycline treated rats.

The ovarian photomicrographs of the penicillin treated rats presented with no pathologic lesions, which suggests the non-toxic effect of the drug on the ovaries at histological level. Similar results were reported by ${ }^{9}$ in Portulaca oleracea treated rats.

The uterine photomicrographs of the penicillin treated rats presented with moderate congestion of the endometria which could also be due to moderate venous thrombosis. Similar result was reported by ${ }^{14}$ in their work on the morphometric evaluation of endometrial blood vessels.

It can therefore be concluded that penicillin probably has pro-fertility effect with a moderate deleterious effect on the uteri at histological level in female Wistar rats. 
However, the effect of this antibiotic on human reproductive function is unknown; nevertheless, considering these findings in animal model, it is recommended that women with infertility problems could take penicillin for infertility therapeutic purpose.

\section{Conflict of Interest}

We vehemently declare that there is no conflict of interests in this research work.

\section{REFERENCES}

1. Kardos N, Demain AL. Penicillin: the medicine with the greatest impact on therapeutic outcomes. Applied Microbiol and Biotech. 2011; 92 (4): 677-87.

2. Jinchun $S$, Laura KS, Sangeeta $K$, Xi $Y$, James G, William S, Donna LM, Richard DB. Evaluating effects of penicillin treatment on the metabolome of rats. J Chromatogr B Analyt Technol Biomed Life Sci. 2013; 932: 134-43.

3. Kaluev AV, Samonina GE, Ashmarin IP. Behavioral effects of penicillin in a test for anxiety in rats. Bulletin of Exptal Biol and Med. 1995; 120: 984-986.

4. Jolanta S, Maciej S, Dorota W, Tadeusz T, Stawomir G. Effects of repeated systemic penicillin injections on nonconvulsive and convulsive epileptic seizures in the rats. Acta Neurobiol Exp. 1995; 55: 281-287.

5. Seifter E, Morris JJ, Levenson SM. Effects of very large doses of penicillin G given orally to rats. Nature. 1968; 217: 1055-1056.

6. Marcondes FK, Bianchi FJ, Tanno AP. Determination of the estrous cycle phases of rats: some helpful considerations. Braz J Bio. 2002; 62(4a): 609 - 614.
7. Long JA, Evans HM. The estrous cycle in the rat and its associated phenomena. Memo Uni Califor. 1922; 6: 1-148.

8. Mandl AM. The phases of the oestrous cycle in the adult white rat. J Exptal Bio. 1951; 28: 576-5 84.

9. Oyedeji KO, Bolarinwa AF. Effects of extracts of Portulaca oleracea on reproductive functions in female albino rats. Afr J Biomed Res. 2010; 13: 213218.

10. Circosta C, Sanogo R, Occhiuto F. Effects of Calotropis proceraon estrous cycle and on estrogenic functionality in rats. Farmaco. 2001; 56: 373-378.

11. Oyedeji KO, Bolarinwa AF, Azeez, AA. Effect of effect of methanolic extract of Vernonia amygdalina on reproductive parameters in male rats. Asian J Pharm Cli Res. 2013; 6 (2): 1-4.

12. Oyedeji KO, Bolarinwa AF, Fashina AM. Effect of alcohol consumption on hematological and reproductive parameters in female albino rats. IOSR J Dent Med Sci. 2013; 3 (5):76-79.

13. Oyedeji KO, Bolarinwa AF, Afolabi OA. Effect of tetracycline on haematological and reproductive parameters in female albino rats. Asian J Pharm and Clin Res. 2013; 6 (2): 227-229.

14. Divya M, Alka MM, Ramadas N, Suneet K, Sharada R, Muktha RP, Poornima B. Morphometric evaluation of endometrial blood vessels. Indian J Path Microbio. 2008; 51(3): 346-350.

Source of Support: The author(s) received no financial support for the research, authorship, and/or publication of this article.

Conflict of Interest: The author(s) declared no potential conflicts of interest with respect to the research, authorship, and/or publication of this article.

For any question relates to this article, please reach us at: editor@globalresearchonline.net New manuscripts for publication can be submitted at: submit@globalresearchonline.net and submit_ijpsrr@rediffmail.com 